\title{
Total phenolic content, FTIR analysis, and antiproliferative evaluation of lupin seeds harvest from western Romania
}

\author{
Corina Danciu' ${ }^{1, A-F}$, loana Zinuca Pavel ${ }^{1, B-C}$, Roxana Babuta ${ }^{1, B-C}$, Alexa Ersilia ${ }^{2, B-C, F}$, Oana Suciu ${ }^{3, E}$, \\ Georgeta Pop ${ }^{2, A, D-E}$, Codruta Soica, ${ }^{1, D-F}$, Cristina Dehelean ${ }^{1, A, D, F}$, Isidora Radulov ${ }^{2, B, E-F}$ \\ 1 University of Medicine and Pharmacy "Victor Babeş", Timişoara, Romania \\ ${ }^{2}$ Banat's University of Agricultural Sciences and Veterinary Medicine "King Michael I of Romania", Timisoara, Romania \\ ${ }^{3}$ Department of Microbiology, Discipline of Hygiene, Faculty of Pharmacy, University of Medicine and Pharmacy "Victor \\ Babeş", Timişoara, România \\ A - Research concept and design, B - Collection and/or assembly of data, C - Data analysis and interpretation, \\ $D$ - Writing the article, E-Critical revision of the article, F-Final approval of article
}

Danciu C, Zinuca Pavel I, Babuta R, Ersilia A, Suciu O, Pop G, Soica C, Dehelean C, Radulov I. Total phenolic content, FTIR analysis, and antiproliferative evaluation of lupin seeds harvest from western Romania. Ann Agric Environ Med. 2017; 24(4): 726-731. doi: 10.26444/aaem/80795

\begin{abstract}
Introduction. Lupinus spp. are herbaceous perennial flowering plants included in the Fabaceae family. Among the approximately 200 species belonging to this genre, Lupinus albus L., also known as white lupin, Lupinus angustifolius L., and narrow-leafed lupin or blue lupin, represent two of the most studied species due to their intense culinary use and potential biological activity. The intention of the study was to characterize total phenolic content, perform FTIR analysis, and antiproliferative effects against A375 human melanoma cells extracts obtained from germinated and ungerminated seeds from Lupinus albus L. and Lupinus angustifolius $L$.

Materials and method. Total phenolic content was assessed using the Folin-Ciocalteu colorimetric method. FTIR spectra were carried out by a Shimadzu Prestige-21 spectrometer in the range $400-4000 \mathrm{~cm}^{-1}$, using KBr pellets and resolution of $4 \mathrm{~cm}^{-1}$. Antiproliferative capacity was screened by employing the MTT (3-(4,5-dimethylthiazol-2-yl)-2,5-diphenyltetrazolium bromide) and scratch assay methods.

Results. The study showed increased values corresponding to total phenolic content for the germinated extracts. FTIR spectra confirmed the presence of genistein and main cinnamic acids derivatives (ferulic, caffeic, rosmarinic, and coumaric acids). All tested extracts showed weak antiproliferative potential against A375 human melanoma cells.

Conclusions. Germination increased the amount of bioactive compounds in the seeds of the two studied species of lupin. FTIR analyses provided an important fingerprint of the chemical composition.
\end{abstract}

\section{Key words}

antiproliferative, FTIR, germination, polyphenols, lupin seeds

\section{INTRODUCTION}

Natural compounds represent a very important source for the discovery of new drugs with important therapeutic activity in different areas of medicine [1]. Nevertheless, research in this area shows that less than $10 \%$ of the world's biodiversity have been screened for possible biological effect, thus, many more primary and secondary plant metabolites await discovery in order to be put into service for the health benefits of the human body [2]. The Fabaceae family, also known under the name of legume, pea, or bean family, provides an increased number of nutraceuticals, plants used both for the nutritional value as well as for their health benefits. Generally, the seeds are used in the alimentary field due to the high amount of proteins, carbohydrates, polyunsaturated fatty acids, dietary fibre, and in the medical field due to the presence of flavonoids, isoflavonoids, poly-hydroxy acids, phytosterols, vitamins and

Address for correspondence: Oana Suciu, Department of Microbiology, Discipline of Hygiene, Faculty of Pharmacy, University of Medicine and Pharmacy "Victor Babes", Timișoara, România

E-mail: oana_suciu96@yahoo.com

Received: 10.08.2017; accepted: 25.11.2017; first published: 15.12 .2017 minerals [3]. Lupinus spp. are herbaceous perennial flowering plants, being part of the Fabaceae family. Among the approximately 200 species belonging to this genre, Lupinus albus L., also known as white lupin, Lupinus angustifolius L., narrow-leafed lupin or blue lupin, represent two of the most studied species due to their intense culinary use and potential biological activity. The most important chemical constituents of the seeds represented by proteins, with percentages in the range of $36-52 \%$, followed by fibres with quantity in the range of $30-40 \%$, and essential oils in amounts with the range of $5-20 \%$. Other chemical constituents worth mentioning, but present only in a concentration under $5 \%$, include oleic and linoleic acids, flavonoids, isoflavonoids, carotenoids, polysaccharides, alkaloids. The amount of the above- mentioned constituents can vary depending on the environment, pedoclimatic and genetic conditions [4-6]. It is also very important to mention that from the point of view of the amount of protein, lupine seeds follow closely soybean seeds, and as a particular advantage, Lupinus spp. can be cultivated in Europe while Glycine spp. prefer pedoclimatic conditions in Asia [4].

Regarding the biological activity of lupin seed extracts, antioxidant activity has been reported [7]. Lampart-Szczapa 
et al., have described the antibacterial activity of lupin seeds extracts on both Gram (+) and Gram (-) strains, and concluded that it is directly correlated with the amount of total polyphenols [8]. Erdemoglu et al., have shown that the alkaloid extract obtained from Lupinus angustifolius L. possesses significant antibacterial and antimitotic activity against $B$. subtilis, S. aureus, $P$. aeruginosa, C. albicans and $C$. kruse, and has a weak potential against E.coli [6]. The group of Sirtori et al., have demonstrated that proteins extracted from white lupin seeds present cholesterol-lowering effects in rats, and augment the activity of the LDL receptor in the human hepatoma HepG2 cell line [9]. Also, the extracts obtained from blue lupin seeds have been reported for their cholesterol-lowering potential using an animal model of intact and ileorectal anastomosed pigs [10]. In the same way, Marchesi et al., have described the hypolipidaemic and anti-atherosclerotic potential of the proteins extracted from the seeds using a rabbit model of atherosclerosis [11]. Its implications in the treatment of type 2 diabetes were assigned to conglutin [12]. Anthelminthic properties for the seeds extract where described by Dubois et al. [13].

The aim of this study is to characterize in terms of total phenolic content, FTIR analysis and antiproliferative effects against A375 human melanoma cells extracts obtained from germinated and ungerminated seeds from Lupinus albus L. and Lupinus angustifolius L.

\section{MATERIALS AND METHOD}

Vegetal extracts. Lupinus albus L. and Lupinus angustifolius L. seeds where obtained from the experimental culture field of Banat's University of Agricultural Sciences and Veterinary Medicine "King Michael I of Romania" in Timisoara. Voucher specimens were identified and deposited in the herbarium of the University of Medicine and Pharmacy "Victor Babeș", Department of Pharmacognosy. Seeds where divided in two groups. One group was stored in standard conditions until analysis and the other group was subjected to germination, as previously described by Andor et al. [4]. For both germinated and ungerminated seeds, extracts were prepared using $80 \%$ ethanol (FALC LCD series ultrasonic bath, for $10 \mathrm{~min}$ at $40 \mathrm{kHz}$ and $28^{\circ} \mathrm{C}$ ). Extraction was repeated three times. A rotary evaporator was used to eliminate the solvent. To simplify the presentation of results, the following letters where assigned: A - ungerminated Lupinus. albus L. seeds extract; B - ungerminated Lupinus angustifolius L. seeds extract; C - germinated Lupinus. albus L. seeds extract; D germinated Lupinus angustifolius L. seeds extract.

Total phenolic content (TP). Determined using the FolinCiocalteu colorimetric method. Seed extracts were diluted $(1: 4, \mathrm{v} / \mathrm{v})$ with water, treated with $20 \mathrm{ml}$ methanol: water $(50: 50, \mathrm{v} / \mathrm{v})$ and maintained at room temperature for one hour. The samples were centrifuged (10 minutes at $450 \mathrm{rot} / \mathrm{min}$ ) and $0.5 \mathrm{ml}$ of supernatant was treated with $1.25 \mathrm{ml}$ FolinCiocalteu reagent diluted 1:10 with water. The samples were incubated for 5 minutes at room temperature and $1 \mathrm{ml}$ $\mathrm{Na}_{2} \mathrm{CO}_{3} 60 \mathrm{~g} / \mathrm{l}$ was added. After $30 \mathrm{~min}$ of incubation at $50^{\circ} \mathrm{C}$, the absorbance of samples was measured at $760 \mathrm{~nm}$. Linearity was obtained between $5-50 \mu \mathrm{g} / \mathrm{ml}$. Results were expressed as mg of gallic acid equivalents per $100 \mathrm{~g}$ fresh weight (FW) sample (mg GAE/100g FW).
Fourier transform infrared spectroscopy (FTIR). Samples were also characterized by means of infrared spectroscopy. FTIR spectra were carried out using a Shimadzu Prestige-21 spectrometer in the range $400-4000 \mathrm{~cm}^{-1}$, using $\mathrm{KBr}$ pellets and resolution of $4 \mathrm{~cm}^{-1}$.

MTT. A375 human melanoma cells were seeded onto a 96well culture plate at a cellular density of $1 \times 10^{4}$ cells/well and attached to the bottom of the well overnight. After 24 hours, $100 \mu \mathrm{L}$ of new medium containing Dulbecco's Modified Eagle's Medium (DMEM; Gibco BRL, Invitrogen, Carlsbad, CA, USA) and 50 and $150 \mu \mathrm{g} / \mathrm{ml}$ of the tested substances (dissolved in dimethyl sulfoxide - DMSO; Sigma-Aldrich Company), were added and incubated for $72 \mathrm{~h}$; the medium was supplemented with $10 \%$ foetal calf serum (FCS; PromoCell, Heidelberg, Germany) and 1\% Penicillin/Streptomycin mixture (Pen/Strep, 10,000 IU/ml; PromoCell, Heidelberg, Germany). The cells were then assayed by the addition of $10 \mu \mathrm{L}$ of $5 \mathrm{mg} / \mathrm{mL}$ MTT solution from the MTT-based in vitro toxicology assay kit (Tox-1; Sigma-Aldrich). The intact mitochondrial reductase converted and precipitated MTT as blue crystals during a $3 \mathrm{~h}$ contact period. The precipitated crystals were dissolved in $100 \mu \mathrm{L}$ of lysis solution (Sigma-Aldrich). The reduced MTT was spectrophotometrically analyzed at 590 and $655 \mathrm{~nm}$, using a microplate reader (Bio-Rad, Hercules, CA, USA). Stock solutions of the tested substances $(10 \mathrm{mg} / \mathrm{ml})$ were prepared in DMSO.

Scratch assay. The migratory ability of selected tumour cells (A375 human melanoma cells and MDA-MB-468 breast carcinoma cells) was examined in vitro by using the scratch assay technique. A number of $2 \times 10^{5}$ cells/well was cultivated in 12-well plates for $48 \mathrm{~h}$ prior to the experiment. A sterile pipette tip was used to draw scratches in well-defined zones of the cells monolayer (confluence of 80-90\%). Cells that detached as a result of the procedure were removed by washing with PBS before stimulation. The cells were stimulated with different selected extracts (50 and $150 \mu \mathrm{g} /$ $\mathrm{ml}$ ) following solubilization in DMSO (stock solution $10 \mathrm{mg}$ / $\mathrm{ml}$ ). Images of the cells in culture were acquired at the starting point of the experiment, and after 4 and $24 \mathrm{~h}$ using an Optika Microscopes Optikam Pro Cool 5 and Optika View software.

Statistics. The Prism software package (Graph Pad Prism 4.03 for Windows) was used for presentation of the experimental data. Results are presented as mean \pm SD. Two way ANOVA was applied to evaluate statistical significance $\left({ }^{*}, \mathrm{p}<0.05\right.$; ${ }^{* *}$, $\mathrm{p}<0.01$; and $\left.{ }^{* * *}, \mathrm{p}<0.001\right)$.

\section{RESULTS}

Total phenolic content of the selected extracts expressed as mg gallic acid equivalents (GAE) per $100 \mathrm{~g}$ sample are shown in Figure 1. It can be observed that the two analyzed lupines species extracts present similar values in terms of total phenolic amount, and that the amount is increased after germination.

The results of the FTIR analysis for samples A, B, C and D are presented in Figure 2. All spectra were recorded between $400-4,000 \mathrm{~cm}^{-1}$. 


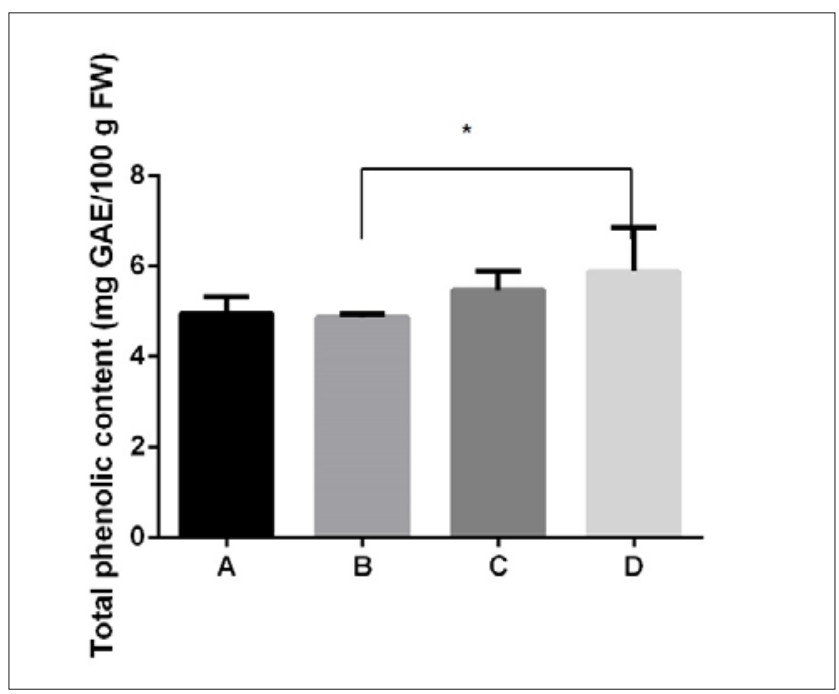

Figure 1. Total phenolic content of the selected extracts expressed as mg gallic acid equivalents per $100 \mathrm{~g} \mathrm{FW}$ sample (unpaired t test, $\mathrm{t}=0,0113$ )

As it can be observed from the FTIR spectra, all samples present the same absorbance bands, the differences between them consisting in the value of the transmittance and in the appearance of the bands (width, sharpness). These findings are predictable since the samples are four extracts obtained from germinated and ungerminated seeds from two different species of lupin, as described in the materials and method section. According to the literature presented in the discussion section, due to the assigned groups to the vibrational mode it can noted that the analyzed samples show correspondence in the occurrence of the main groups. The assigned groups (due to the f molecules vibration) belong to compounds identified by means of HPLC (isoflavone, main cinnamic acids derivatives).

The MTT proliferation assay showed that at the tested concentrations, using an incubation time of $72 \mathrm{~h}$, the extracts of both lupin species presented weak (inhibition

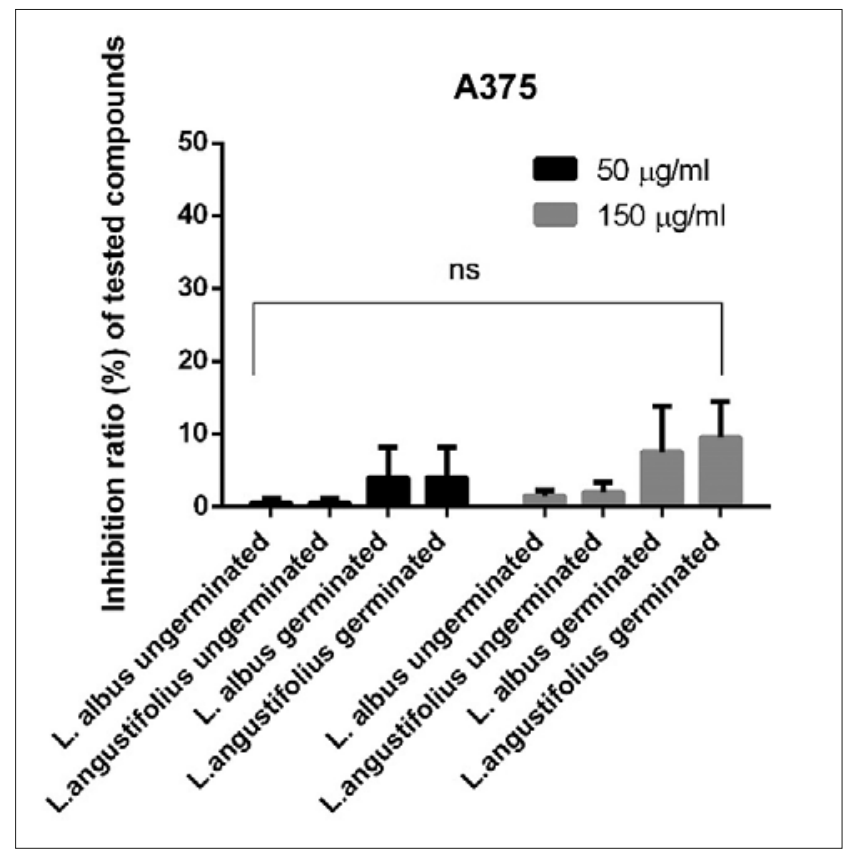

Figure 3. Antiproliferative effect of Lupinus albus L. and Lupinus angustifolius L. ungerminated and germinated seeds extract against A375 human melanoma cell line

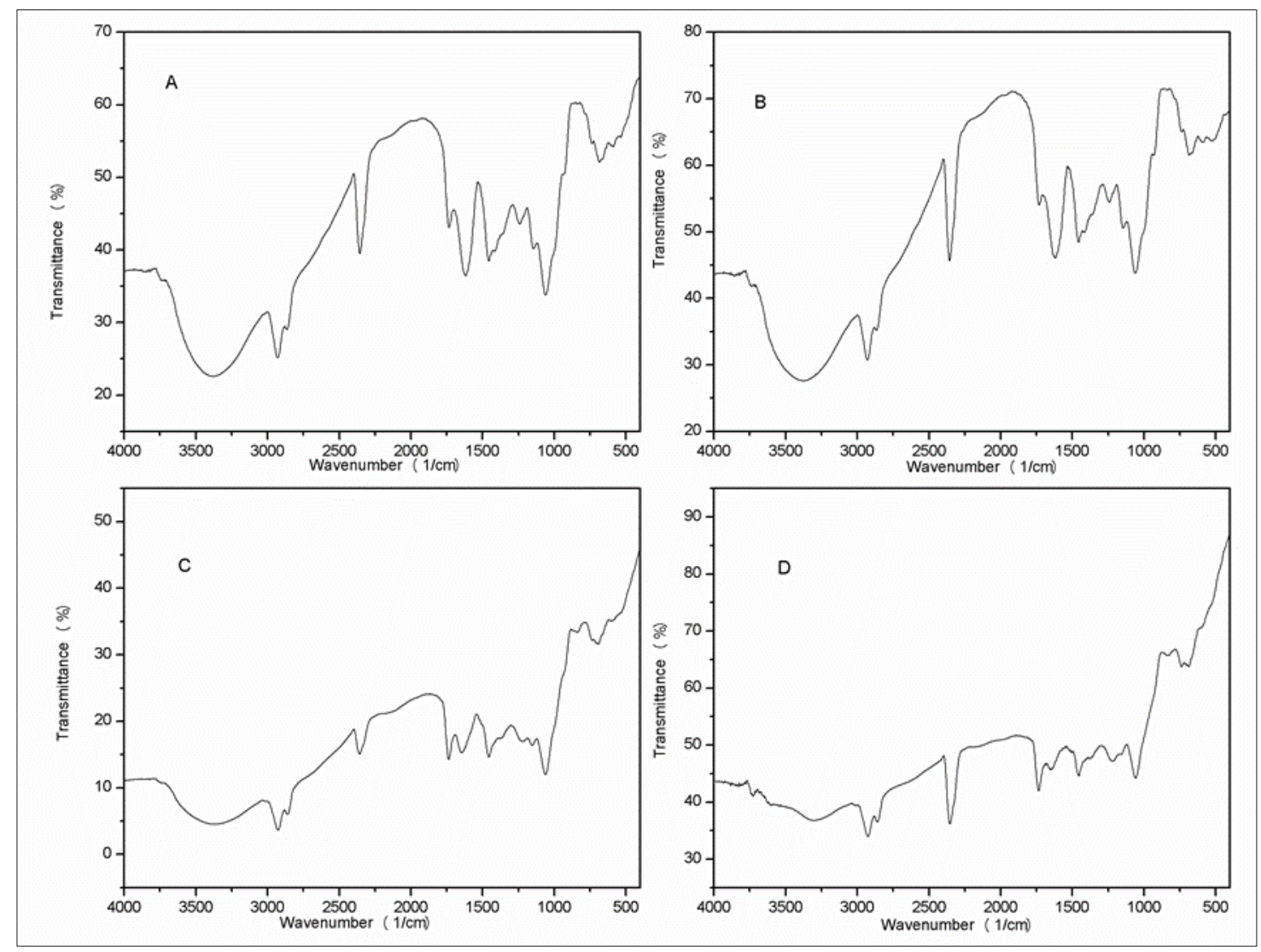

Figure 2. FTIR spectra for sample A-D 
ratio under 20\%) antiproliferative activity against A375 human melanoma cells. As a particular observation, the antiproliferative activity was slightly increased in the case of both germinated seeds extracts, thus being proof of the augmentation of the concentration of the bioactive compounds, but still not enough to proclaim a significant antiproliferative effect (Fig. 3).

The scratch assay strengthens the findings about the weak antiproliferative effect of the sample selected cell lines. Cell migration was not inhibited for none of the two tested cell lines after incubation with the highest tested concentration of the four samples, namely $150 \mu \mathrm{g} / \mathrm{ml}$. Again in case of incubation with germinated seeds extract migration seems to be slightly diminished compared to the groups incubated with ungerminated seeds extract (Fig. 4).

\section{DISCUSSION}

The amount of polyphenols in vegetal products reflects their antioxidant capacity, and consequently, their potential in preventing various oxidative stress associated diseases. Given their multiple benefits there has been much interest in the study of this plant's secondary metabolites [14, 15]. The amount of polyphenols in a vegetal product varies depending on the extraction method involved [16]. Wang et al. showed that the amount of polyphenols for Lupinus albus L. seeds varies between $444.4-1661.2 \mathrm{mg} / 100 \mathrm{~g}$ of vegetal product, whereas for Lupinus angustifolius L. seeds it varies between 535.1 - $578.4 \mathrm{mg} / 100 \mathrm{~g}$ [17]; the total polyphenols in the extracts of ungerminated seeds of the two Lupinus spp. detected during the present investigation are consistent with previous studies [18]. Germination of different legumes increases the amount of bioactive compounds, thus providing useful products for nutraceutical applications [19]. Duenas

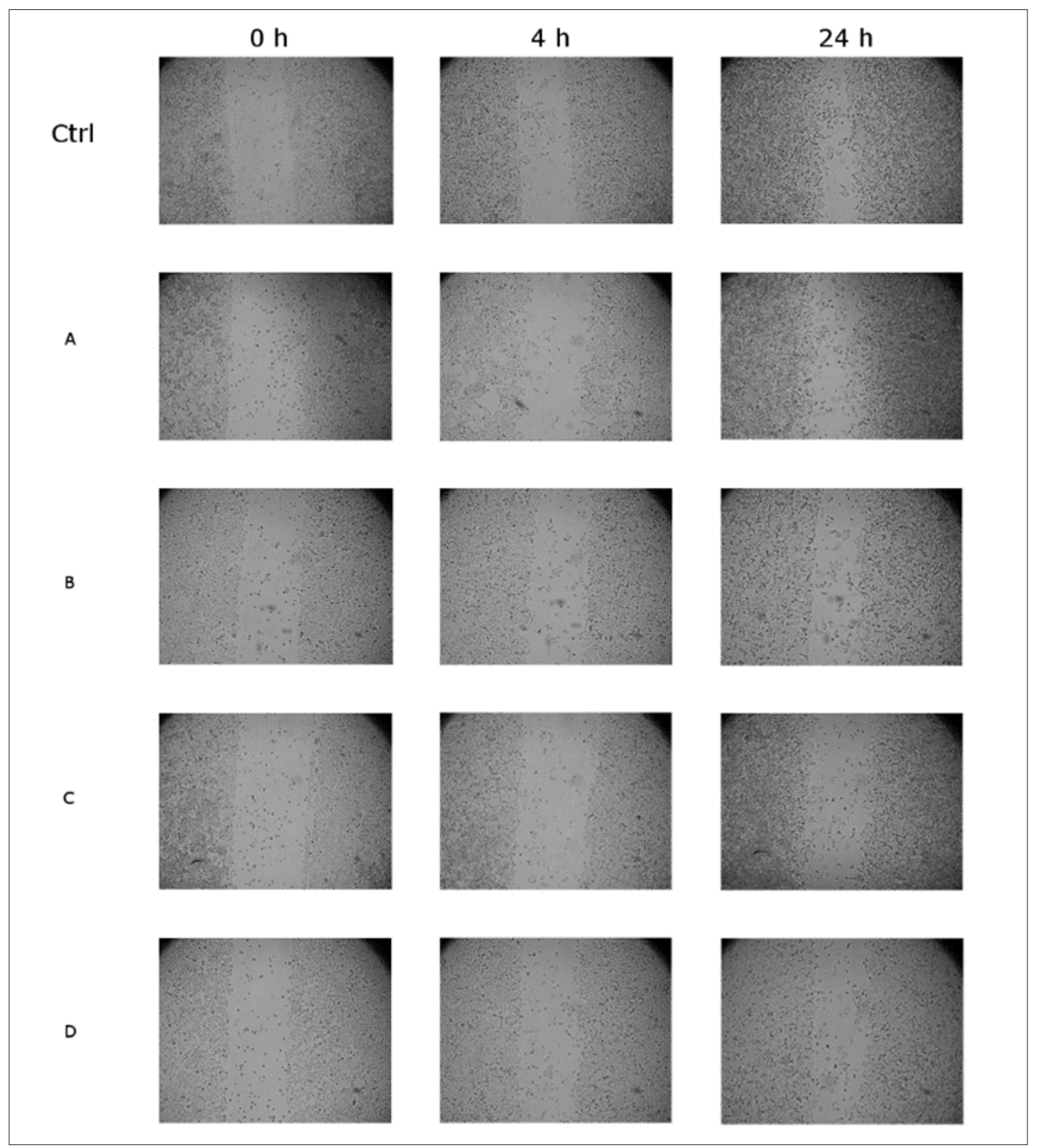

Figure 4. Anti-migration capacity of Lupinus albus L. and Lupinus angustifolius L. ungerminated and germinated seeds extract against A375 human melanoma cell line 
et al. have depicted germination as a method of increasing the polyphenol content as well as antioxidant activity for Lupinus angustifolius L. [20]. The results from the current study are in agreement with previous reports from the literature, as explained in the Results section, in which it was possible to detect higher amounts of polyphenols in the germinated seeds of the two Lupinus sp.

Some of the main phytochemicals present in the analyzed samples were established by means of HPLC in a previous study [4]. The targeted chemical compounds identified by HPLC were the isoflavone genistein, together with caffeic coumaric, ferulic, and rosmarinic acids. The vibrational spectrum of any molecule has a distinctive property and is characteristic for that molecule. In this case, each analyzed sample had more than one compound, which make it difficult to correlate the vibrational band from the spectra with its correspondent compound. The disadvantage of infrared spectroscopy is the overlapping of the bands, resulting in complicated attribution of the identified group; this aspect is emphasized when the analyzed sample is formed by a mixture of compounds. The FTIR analysis has its own limitation [21], it can help elucidate the structure of a known compound but cannot establish with certainty the identity in mixtures of compounds.

According to [22], the region for functional groups is between 4,000-1,300 $\mathrm{cm}^{-1}$. Structures containing: carbonyl groups are located in the $1,850-1,540 \mathrm{~cm}^{-1}$ region, strong skeletal bands for aromatics in the $1,600-1,300 \mathrm{~cm}^{-1}$ region (resulted in a ring structure from stretching of the carboncarbon bonds), aliphatic structures are located in the region $909-650 \mathrm{~cm}^{-1}$. Also, the fingerprint region is mentioned, which is not to be considered between $1,300-909 \mathrm{~cm}^{-1}$.

In the book by B. Stuart [23], the author described that the alifatic compounds type methylene groups present stretching at 2,930 $\mathrm{cm}^{-1}$ (asymmetric) and at $2850 \mathrm{~cm}^{-1}$ (symetric); the $=\mathrm{C}-\mathrm{H}$ binding between $700-300 \mathrm{~cm}^{-1}$; combination bands - overtone in the region 2,000-1,700 $\mathrm{cm}^{-1}$. For the aromatic compounds, C-H streching are in the $3,100-3,000 \mathrm{~cm}^{-1}$ area; in the 2,000-1,700 $\mathrm{cm}^{-1}$ region there are located a weak combination, overtone bands, and substitution of the benzene ring; $1,650-1430 \mathrm{~cm}^{-1}$ is the region for skeletal vibration $(\mathrm{C}=\mathrm{C}$ streching); in-plane binding of $\mathrm{C}-\mathrm{H}$ is located between $1,275-1,000 \mathrm{~cm}^{-1}$; out-of plane binding appear in the region $900-690 \mathrm{~cm}^{-1}$.

A comprehesive study about trans-cinnamic acids which brings together data obtained from both FT-Raman and FTIR spectra offers important information regarding the characteristic absorptions bands for caffeic, coumaric, ferulic, and rosmarinic acids [24]. At values of 3,000 $\mathrm{cm}^{-1}$ the vibration are attributed to stretching the $\mathrm{C}-\mathrm{H}$ ring and stretching $=\mathrm{C}-\mathrm{H}$; around $1,600 \mathrm{~cm}^{-1}$ are located the bands for symmetric and asymmetric stretching in $\mathrm{C}=\mathrm{O}$; between $1,430-1,580 \mathrm{~cm}^{-1}$ are the bands corresponding to stretching vibration in the $\mathrm{C}-\mathrm{C}$ ring; in the range $1,030-1,180 \mathrm{~cm}^{-1}$ are located the bands in plane deformation of the $\mathrm{C}-\mathrm{H}$ ring. At $1,267 \mathrm{~cm}^{-1}$ is presented the position for in-plane deformation of $=\mathrm{C}-\mathrm{H}$, at $683 \mathrm{~cm}^{-1} \mathrm{COOH}$ scissoring and at $769 \mathrm{~cm}^{-1}$ out of plane deformation of the $\mathrm{C}-\mathrm{H}$ ring [24]. The out-of plane, inplane and out-of plane ring deformation are also presented. It is important to mention that in a mixture such as in the presented case, the extracts, a multitude of bands that overlaps and perhaps converge into a broader band, or could shift to higher wavenumber, can be detected on the spectra.
Crupi at al. [25] stress that in the range 4,000-2,000 $\mathrm{cm}^{-1}$ genistein presents an absorption band at approximately $3,405 \mathrm{~cm}^{-1}$, normally attributed to the $\mathrm{O}-\mathrm{H}$ stretching vibration, overlapped with a band located at $3,084 \mathrm{~cm}^{-1}$ attributed to $\mathrm{C}-\mathrm{H}$ stretching vibration. In the presented case, the broad band located at over $3,000 \mathrm{~cm}^{-1}$ could be assigned for this kind of vibrational behaviour. Usually, the hydroxyl groups are present in the range 3,100-3,700 $\mathrm{cm}^{-1}$ [26]; however, in mixtures and complex molecules these groups are overlapped, resulting in very broad bands, that lead to a difficult correlation of the spectral profile.

The anti-proliferative and anti-migratory effects are frequently discussed together in order to get an idea of a possible chemopreventive effect of the tested sample [27]. The literature is very poor in reports regarding results about the anti-proliferative, respective anti-migratory effect of extracts obtained from lupin seeds which resulted in the presented study to perform screening regarding the chemopreventive potential of this vegetal product. As can be observed from the results section, none of these activities are notable; thus results of this study are not helpful for providing data about a significant biological activity to scientists in the field with similar question to those posed by the authors of this study.

However, it can be clearly seen that the anti-proliferative and anti-migratory effects are increased for the germinated samples, compared to ungerminated ones. Germination is a very good and accepted method used for the augmentation of the amount of the biological active substances [28]. In a similar approach, Andor et al., tested the antiproliferative activity of germinated and ungerminated extracts of lupines seeds against breast (MCF7, MDA-MB-231 cell lines) ovarian (A2780cell line), and cervical cancer ( $\mathrm{SiHa}$ cell line), and described a similar decreased activity, with the observation that germination slightly increased the biological effect [4].

\section{CONCLUSIONS}

Extracts obtained from germinated seeds contain an increased amount of polyphenols in comparison to extracts obtained from ungerminated seeds. FTIR spectra confirmed the presence of genistein and main cinnamic acids derivatives (ferulic, caffeic, rosmarinic, and coumaric acids). All tested extracts showed weak antiproliferative potential against A375 human melanoma cell line.

\section{Acknowledegments}

The chemical sections were performed in the Interdisciplinary Research Platform of the Banat University of Agricultural Sciences and Veterinary Medicine "King Michael I" of Romania in Timisoara, Romania.

\section{REFERENCES}

1. Cragg GM, Newman DJ Natural products: a continuing source of novel drug leads. Biochimica et Biophysica Acta. 2013; 1830(6): 3670-3695.

2. Dias DA, Urban S, Roessner U. A Historical Overview of Natural Products in Drug Discovery. Metabolites. 2012; 2(2): 303-336.

3. Gulewicz P, Martinez-Villaluenga C, Kasprowicz-Potocka M, Frias J. Non-Nutritive Compounds in Fabaceae Family Seeds and the Improvement of Their Nutritional Quality by Traditional Processing - a Review. Pol J Food Nutrition Sci. 2014; 64(2): 75-89.

4. Andor B, Danciu C, Alexa E, Zupko I, Hogea E, Cioca A, et al. Germinated and Ungerminated Seeds Extract from Two Lupinus 
Species: Biological Compounds Characterization and In Vitro and In Vivo Evaluations. Evidence-Based Complementary and Alternative Medicine.2016;2016(7638542):1-8. http://dx.doi. org/10.1155/2016/7638542

5. Monteiro MRP, Costa ABP, Campos SF, Silva MR, da Silva CO, Martino HSD, Silvestre MPC. Evaluation of the chemical composition, protein quality and digestibility of lupin (Lupinus albus and Lupinus angustifolius), O mundo da Saude. 2014; 38(3): 251-259.

6. Erdemoglu N, Ozkan S, Tosun F. Alkaloid profile and antimicrobial activity of Lupinus angustifolius L. alkaloid extract. Phytochemistry Rev. 2007; 6(1): 197-201.

7. Tsaliki E, Lagouri V, Doxastakis G. Evaluation of the antioxidan activity of lupin seed flour and derivatives (Lupinus albus ssp. Graecus). Food Chemistry. 1999; 65(1): 71-75.

8. Lampart-Szczapa E, Siger A, Trojanowska K, Nogala-Kalucka M, Malecka M, Pacholek B. Chemical composition and antibacterial activities of lupin seeds extracts. Nahrung. 2003; 47(5): 286-290.

9. Sirtori CR, Lovati MR, Manzoni C, Castiglioni S, Duranti M, Magni C, et al. Proteins of White Lupin Seed, a Naturally Isoflavone-Poor Legume, Reduce Cholesterolemia in Rats and Increase LDL Receptor Activity in HepG2 Cells. J Nutr. 2004; 134(1): 18-23.

10. Martins JM, Riottot M, Abreu MC de, Viegas-Crespo AM, Lança MJ, Almeida JA, et al. Cholesterol-lowering effects of dietary blue lupin (Lupinus angustifolius L.) in intact and ileorectal anastomosed pigs. J Lipid Res. 2005; 46(7): 1539-1547.

11. Marchesi M, Parolini C, Diani E, Rigamonti E, Cornelli L, Arnoldi A, et al. Hypolipidaemic and anti-atherosclerotic effects of lupin proteins in a rabbit model. Br J Nutr. 2008; 100(4): 707-710.

12. Lovati MR, Manzoni C, Castiglioni S, Parolari A, Magni C, Duranti M. Lupin seed $\gamma$-conglutin lowers blood glucose in hyperglycaemic rats and increases glucose consumption of HepG2 cells. Br J Nutr. 2012; 107(1): 67-73.

13. Dubois O, Sallé G, Février H, Magnin-Robert JB, Harzic N, Charvet C, et al. Characterization of anthelminthic properties of the lupine seed, Lupinus spp. Planta Medica. 2016; 82(S 01): P1006.

14. Pandey KB, Rizvi SI. Plant polyphenols as dietary antioxidants in human health and disease. Oxid Med Cell Longev. 2009; 2(5): 270-278

15. Habauzit V, Morand C. Evidence for a protective effect of polyphenolscontaining foods on cardiovascular health: an update for clinicians. Ther Adv Chronic Dis. 2012; 3(2): 87-106.
16. Dai J, Mumper RJ. Plant phenolics: extraction, analysis and their antioxidant and anticancer properties. Molecules. 2010;15(10):73137352.

17. Wang S, Clements J. Antioxidant activities of lupin seeds. In: Lupins for Health and Wealth. Proceedings of the 12th International Lupin Conference, Fremantle, Western Australia. 2008; 14-18: 546-551.

18. Siger A, Czubinski J, Kachlicki P, Dwiecki K, Lampart-Szczapa E, Nogala-Kalucka M. Antioxidant activity and phenolic content in three lupin species. J Food Comps Anal. 2012; 25(2): 190-197.

19. Lin PY, Lai HM. Bioactive compounds in legumes and their germinated products. J Agr Food Chem. 2006; 54(11): 3807-3814.

20. Duenas M, Hernandez T, Estrella I, Fernandez D. Germination as a process to increase the polyphenol content and antioxidant activity of lupin seeds (Lupinus angustifolius L.). Food Chem. 2009; 117(4): 599-607.

21. Coates J. Interpretation of Infrared Spectra, A Practical Approach. In Encyclopedia of Analytical Chemistry, Meyers R.A. (Ed.); John Wiley \& Sons, Ltd: Chichester, UK, 2000; 10815-37.

22. Segneanu AE, Gozescu I, Dabici A, Sfirloaga P, Szabadai, Z. Organic Compounds FT-IR Spectroscopy, Macro To Nano Spectroscopy, Uddin J. (Ed.), InTech, 2012.

23. Stuart BH Infrared Spectroscopy: Fundamentals and Applications. Methods. Analytical Techniques in the Sciences, Ando DJ (Ed.), England, Wiley, 2004; 8.

24. Nolasco M, Amado AM, Ribeiro-Claro PJA. Effect of hydrogen bonding in the vibrational spectra of trans-cinnamic acid. J Raman Spectrosc. 2009; 40(4): 394-400.

25. Crupi V, Ficarra R., Guardo M, Majolino D, Stancanelli R, VenutiV UV-vis and FTIR-ATR spectroscopic techniques to study the inclusion complexes of genistein with $\beta$-cyclodextrins. J Pharmaceut Biomed Analysis. 2007; 44(1): 110-117.

26. Silverstein RM, Webster F., Kiemle DJ. Spectrometric Identification of Organic Compounds. 7th ed.; John Wiley and Sons: Hoboken, NJ, 2005.

27. Timeus F, Crescenzio N, Fandi A, Doria A, Foglia L, Cordero di Montezemolo L. In vitro antiproliferative and antimigratory activity of dasatinib in neuroblastoma and Ewing sarcoma cell lines. Oncol Reports. 2008; 19(2): 353-359.

28. Bau HM, Villaume C, Méjean L. Effects of soybean (Glycine max) germination on biologically active components, nutritional values of seeds, and biological characteristics in rats. Nahrung. 2000; 44(1): 2-6. 